\title{
LA GOBERNANZA REGIONAL DEL DESARROLLO EN AMÉRICA DEL SUR (2000-2015) ${ }^{1}$ \\ Regional development governance in South America (2000-2015)
}

\author{
STEFANO PALESTINI \\ Universidad Libre de Berlín \\ stefano.palestini@eui.eu
}

Cómo citar/Citation

Palestini, S. (2017).

La gobernanza regional del desarrollo

en América del Sur (2000-2015).

Revista de Estudios Políticos, 176, 191-222.

doi: https://doi.org/10.18042/cepc/rep.176.06

\section{Resumen}

El artículo presenta y discute a través de una perspectiva comparada, el concepto de "gobernanza regional del desarrollo" (GRD) como una modalidad de cooperación sur-sur. En la primera parte del artículo se demuestra la relevancia renovada adquirida por estas iniciativas, luego de un período de marcada disociación entre regionalismo y desarrollo durante las décadas del regionalismo abierto y de las reformas neoliberales de mercado. En la segunda parte del artículo se analiza, a través de process tracing analysis y de un extenso trabajo de campo, la experiencia de la cooperación en infraestructura en América del Sur durante el período 2000-2015 como un ejemplo de GRD, identificando los factores que intervienen en la implementación de bienes colectivos en la región. El artículo concluye enfatizando la urgencia de fortalecer estas modalidades regionales de cooperación sur-sur en un contexto económico global particularmente difícil para América Latina.

1 Este artículo se enmarca en el proyecto «Diseño institucional en integración regional comparada (InDeCRI)», código CSO 2016-76130-P, financiado por la Agencia Española de Investigación. El artículo se benefició de la investigación realizada por el autor en el Colegio de Graduados, hospedado en la Universidad Libre de Berlín y financiado por la Deutsche Forschungsgemeinschaft: «The Transformative Power of Europe». 


\section{Palabras clave}

América del Sur; bienes públicos; cooperación Sur-Sur; cooperación internacional; integración regional; IIRSA; Unasur; bancos regionales de desarrollo; regionalismo.

\section{Abstract}

The article discusses the concept of Regional Development Governance (RDG) as a type of South-South cooperation. RDG initiatives have acquired new salience after two decades of new regionalism and neoliberal reforms in which "development» and "regionalism» became increasingly dissociated. The article analyses the experience of infrastructure cooperation in South American in the period 2000-2015, as an example of RDG. Through the use of process tracing analysis and extensive fieldwork, it identifies the factors that intervene in the implementation of collective goods in the region. The article concludes by emphasizing the necessity to strengthen this type of initiative especially in the low economic growth conjuncture that Latin American countries are facing.

\section{Keywords}

South America; public goods; south-south cooperation; international cooperation; regional integration; IIRSA; Unasur; regional development banks; regionalism. 


\section{SUMARIO}

I. INTRODUCCIÓN. II. GOBERNANZA REGIONAL DEL DESARROLLO EN PERSPECTIVA COMPARADA. 1. Regionalismo desarrollista (1940-1970). 2. Regionalismo abierto y neoliberalismo (1980 en adelante). 3. Formas emergentes de gobernanza regional del desarrollo (1990 en adelante). III. LA GOBERNANZA REGIONAL DEL DESARROLLO EN ACCIÓN: LA COOPERACIÓN SECTORIAL EN INFRAESTRUCTURA EN AMÉRICA DEL SUR (2000-2015). 1. Marco conceptual y metodológico. 2. Presentación de los hallazgos. IV. CONCLUSIONES: DESAFíOS PARA LA GOBERNANZA REGIONAL DEL DESARROLLO EN UN CONTEXTO GLOBAL INCIERTO. BIBLIOGRAFIA.

\section{INTRODUCCIÓN}

Desde fines de la Segunda Guerra Mundial, y con especial énfasis desde la década de los años sesenta, los Gobiernos en diversas regiones del globo han visto en la asociación y cooperación con los países vecinos un camino posible para mejorar las condiciones económicas y sociales de sus propios pueblos. Se puede decir, por tanto, que regionalismo y desarrollo — en tanto componentes del discurso de la modernidad- han estado históricamente vinculados, aunque las formas específicas de dicho vínculo han experimentado transformaciones de la mano del cambio en las estructuras de poder y del cambio en las ideas acerca de cuáles son los fines deseables del desarrollo y cuáles los medios para alcanzarlo.

En las décadas de los años cincuenta y sesenta tendió a imponerse un consenso según el cual el desarrollo de las regiones económicamente rezagadas iba a ser el resultado del uso planificado y coordinado de la autoridad estatal a través de la integración de los sistemas productivos nacionales y de la convergencia de políticas públicas. Fueron los años de lo que John Sloan (1971) denominara un «regionalismo desarrollista» paralelo a la implementación de un sistema internacional de cooperación para el desarrollo a nivel global con instituciones especializadas tales como el Programa de las Naciones Unidas para el Desarrollo (PNUD) y la Asociación de Desarrollo Internacional (AID). La Conferencia de Bandung y el posterior establecimiento de la Conferencia de las Naciones Unidas sobre Comercio y Desarrollo (UNCTAD) afianzarían por su parte la importancia de lo que décadas más tarde se denominaría la cooperación sur-sur. 
A finales de la década de los setenta y con mayor fuerza en la década de los ochenta, el lenguaje para referirse al regionalismo y al desarrollo sufrió importantes transformaciones, imponiéndose el supuesto de que el desarrollo sería el resultado de la coordinación descentralizada de agentes privados operando de acuerdo a señales de mercado. Así, por ejemplo, bienes colectivos que en las décadas anteriores se asumían como responsabilidad del Estado y de la cooperación entre Estados, tales como la infraestructura de transporte, energía y telecomunicaciones, comenzaron a ser concebidos como resultado de la acción de actores privados actuando a través de mecanismos de mercado. La privatización, la liberalización y la reforma regulatoria pasaron a tener prioridad sobre la coordinación de políticas públicas y la cooperación internacional y regional. Como resultado de este cambio de ideas, regionalismo y desarrollo terminaron siendo conceptos disociados.

Sin embargo, ya a finales de los años noventa un número de iniciativas surgidas en el marco de proyectos regionales comenzó a desafiar, por una parte, la creencia en la automaticidad de los mercados y, por otra, la reducción de la cooperación para el desarrollo a fines exclusivamente humanitarios. Sin necesariamente ser un retorno al «regionalismo desarrollista» de las décadas de los años cincuenta y sesenta, estas iniciativas se pueden comprender como una gobernanza regional del desarrollo (Bruszt y Palestini, 2016), orientada a articular y coordinar las políticas públicas y los recursos y capacidades existentes en contextos regionales concretos.

Este artículo tiene el propósito de profundizar en el concepto de "gobernanza regional del desarrollo» (GRD) con un foco específico en América del Sur en cuanto subregión de América Latina y el Caribe. América Latina y sus subregiones representan hoy uno de los contextos regionales más idóneos para estudiar la relación entre regionalismo y desarrollo, no solo por el intenso proceso de diseño de instituciones en el que los Gobiernos de la región se han embarcado desde hace ya más de dos décadas (Dabène, 2009; Malamud, 2013; Nolte, 2014), sino también por la importante elaboración conceptual sobre nuevas modalidades de cooperación para el desarrollo, particularmente cooperación sur-sur. La cooperación sur-sur ha sido definida en la región sobre la base de un fortalecimiento mutuo entre oferente y receptor, reciprocidad, responsabilidad compartida y horizontalidad bajo el estricto respeto de la soberanía nacional y la no injerencia, principios que también encontramos en la mayoría de los proyectos de regionalismo que hoy conviven en América Latina en general, y en América del Sur en particular.

El artículo está dividido en tres partes además de esta introducción. En la primera parte se presenta el concepto de GRD mostrando evidencia histórica y comparada de cómo se han vinculado regionalismo y desarrollo en 
iniciativas concretas en distintos rincones del globo. La segunda parte analiza, bajo la forma de un estudio de caso, un ejemplo contemporáneo de GRD en América del Sur. A través del uso de process tracing analysis y un extensivo trabajo de campo, se analiza el caso de la cooperación sectorial en el área de infraestructura entre los años 2000 y 2015. A través de este estudio de caso se identifican los factores y mecanismos que permiten implementar bienes colectivos regionales con beneficios tangibles para la población. El artículo finaliza con una discusión de los principales desafíos que enfrenta la consolidación de iniciativas de GRD en cuanto una modalidad posible de cooperación sur-sur.

\section{GOBERNANZA REGIONAL DEL DESARROLLO EN PERSPECTIVA COMPARADA}

En este artículo se entiende por GRD iniciativas a través de las cuales actores estatales y no estatales de dos o más países en una región producen programas y proyectos orientados al desarrollo económico y social de sus pueblos en el marco de un proyecto de regionalismo (véase Bruszt y Palestini, 2016). Esta definición general necesariamente debe ser problematizada cuando se asume una perspectiva histórica y comparada. En efecto, a través de una mirada histórica se hace evidente que el significado de "desarrollo", así como el de "gobernanza», han cambiado a lo largo del tiempo de acuerdo a las definiciones y prácticas de diferentes comunidades epistémicas (para una visión comprensiva, véase Rist, 2006; para una visión crítica, Escobar, 1995).

Así, por ejemplo, para la teoría de la modernización y para ciertas variantes de la teoría de la dependencia, "desarrollo" significaba primordialmente la transformación productiva de las economías nacionales y su inserción en la división internacional del trabajo, atribuyendo un rol fundamental en este proceso al Estado y a la inversión pública (véanse Rostow, 1966; Cardoso y Faletto; 1979; Larrain, 1989). Para economistas de formación neoclásica, en cambio, "desarrollo» se limita a mejoras en la competitividad de ciertos sectores de las economías nacionales en mercados regionales y globales, lo que permite un aumento en la renta o producto de una economía. En esta segunda acepción neoclásica, «desarrollo" queda reducido a "crecimiento económico» (Bhagwati, 1993; OMC y OCDE, 2013).

También el concepto de "gobernanza» tiende a fluctuar entre dos significados distintos. Una primera conceptualización enfatiza la coordinación centralizada entre autoridades públicas, mientras que una segunda entiende gobernanza como coordinación descentralizada basada en la acción de agentes 
privados que compiten y se coordinan a través de precios y otras señales de mercado. Concepciones intermedias entre estos dos polos admiten la coordinación de agentes privados, pero generalmente subordinados a algún tipo de jerarquía pública (Lapavitsas y Noguchi, 2005; Wade, 2011; Rodrik et al., 2004; Cimoli et al., 2011).

Si combinamos estos tipos ideales de «desarrollo» y de "gobernanza» obtenemos un espacio esquemático sobre el que podemos situar la trayectoria histórica de la Gobernanza Regional del Desarrollo, tal como se observa en la figura 1 .

Figura 1. Trayectoria de la GRD

Concepción de Desarrollo

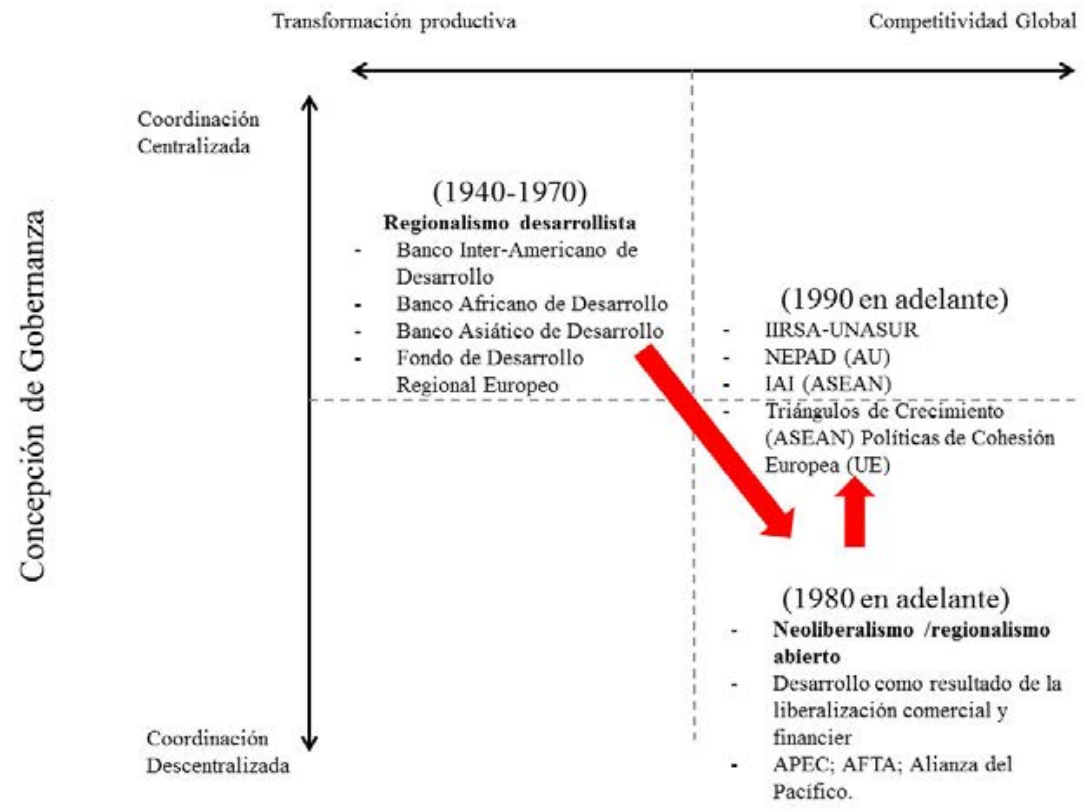

Fuente: adaptado de Bruszt y Palestini (2016). Acrónimos: AFTA (Área de Libre Comercio de ASEAN); APEC (Cooperación Económica del Asia Pacífico); ASEAN (Asociación de Naciones del Sudeste Asiático); UE (Unión Europea); IAI (Iniciativa para la Integración de ASEAN); IIRSA (Iniciativa para la Integración de la Infraestructura Regional de Sudamérica), NEPAD (Nueva Asociación para el Desarrollo de África); UNASUR (Unión de Naciones Suramericanas). 


\section{REGIONALISMO DESARROLLISTA (1940-1970)}

Es posible distinguir un primer período de iniciativas fuertemente influenciadas por las ideas de la teoría de la modernización que entendía el desarrollo como la trayectoria de economías nacionales de base agrícola hacia economías industrializadas y de mayor capacidad tecnológica. Las iniciativas de lo que John Sloan (1971) llamó el "regionalismo desarrollista» se caracterizaban por la coordinación entre gobiernos y autoridades públicas nacionales y subnacionales a través de planificación centralizada, cooperación intergubernamental y, de ser posible, supervisión supranacional (Perroux, 1955; Prebisch, 1963; Tinbergen, 1965).

Quizá el ejemplo más paradigmático de este período sean los primeros tres bancos regionales de desarrollo: el Banco Interamericano de Desarrollo (1959), el Banco Africano de Desarrollo (1964) y el Banco Asiático de Desarrollo (1966). A nivel subregional, la Corporación Andina de Fomento (CAF) y el Banco Centroamericano para la Integración Económica (BCIE) también fueron inspirados por estas ideas. Es interesante mencionar que las ideas que inspiraron la creación de estas instituciones y políticas provenían de economistas sudamericanos como Prebisch, así como de economistas de Europa oriental como Rosenstein-Rodan, que contribuyeron a afianzar la idea, hasta el momento inconcebible, de que era posible promover el desarrollo económico a través de instituciones internacionales (Helleiner, 2009). Estas ideas se basaban en el supuesto de que bajo términos de intercambio desfavorables entre las economías centrales y las periféricas, el regionalismo podía ser un instrumento para apuntalar y promover el proceso de transformación productiva de las economías retrasadas (CEPAL, 1959; Prebisch, 1963; Dosman, 2006).

\section{REGIONALISMO ABIERTO Y NEOLIBERALISMO (1980 EN ADELANTE)}

Hacia fines de 1970, las ideas «desarrollistas» fueron perdiendo influencia entre los círculos epistémicos, especialmente de los economistas que trabajaban en las instituciones multilaterales. $\mathrm{El}$ «desarrollo» fue redefinido como resultado del fomento de la competitividad global a través de políticas orientadas a eliminar las distorsiones sobre los precios (to get the prices right), de modo que permita la coordinación descentralizada de agentes privados que asignarían los recursos de modo racional. De este modo los sectores económicos más competitivos (sin importar si eran industrializados o primarios) alcanzarían mercados globales y podrían atraer inversión extranjera directa. El rol dejado a los gobiernos y autoridades públicas sería de mera «integración negativa», es decir, reducción de las barreras arancelarias y no arancelarias para permitir el progresivo flujo libre de bienes, en un área de libre comercio, y 
finalmente de fuerza de trabajo y de capitales, en un mercado común (Balassa, 1962; Bhagwati, 1993).

La política de reducir las barreras «en la región», para atraer inversión desde «fuera de la región» o «regionalismo abierto» como vino a ser llamado por la CEPAL (1994), dejó poco espacio para iniciativas de GRD, y se transformó en el paradigma dominante de nuevas organizaciones regionales, tales como la APEC. Paralelamente, el Banco Mundial y los bancos regionales de desarrollo reorientarían sus actividades hacia programas para el alivio de la pobreza, por una parte, y para el ajuste estructural de las economías nacionales promoviendo la venta de activos públicos así como reformas regulatorias, y rezagando a un segundo o tercer plano el apoyo al regionalismo. El «ajuste con rostro humano» y los «mercados amigables con la gente» serían los eslóganes que en la década de los noventa intentarían congeniar reformas neoliberales, por una parte, con humanitarismo, por otra (PNUD 1993; Banco Mundial, 1994; Culpeper, 1997; Rist, 2006; Babb, 2009; Vivares, 2013).

En el contexto latinoamericano, la Alianza del Pacífico (AP), creada en 2012 e integrada por Chile, Colombia, Perú y México, es un claro ejemplo de que el paradigma del regionalismo abierto no ha perdido su influencia, y que aún tiene manifestaciones institucionales contemporáneas. La AP no posee una secretaría permanente, por lo que difícilmente puede considerarse una organización regional, y su principal objetivo es convertirse en una plataforma de inversiones con un especial énfasis en las economías del Asia Pacífico.

\section{FORMAS EMERGENTES DE GOBERNANZA REGIONAL DEL DESARROLLO (1990 EN ADELANTE)}

El vínculo entre desarrollo y regionalismo, disociado por el neoliberalismo y el regionalismo abierto, se ha vuelto a recomponer en algunas iniciativas que, si bien se iniciaron tibiamente en la década de mayor apogeo del consenso neoliberal en 1990, han asumido mayor vigor desde inicios del nuevo milenio. Como la figura 1 muestra, estas nuevas iniciativas se sitúan «en medio" de las otras dos categorías. Por una parte, los objetivos de estas iniciativas son más modestos que los programas desarrollistas orientados a la completa transformación productiva de las economías nacionales. Por otra parte, estas nuevas iniciativas rechazan el supuesto de que mercados liberalizados contribuirán, de por sí, al desarrollo de las economías y sociedades. Detrás de estas iniciativas está más bien el supuesto de que la existencia de asimetrías y desigualdades entre economías nacionales y subnacionales puede reducir notablemente los beneficios obtenidos de la inserción en mercados regionales y globales (Delors, 1989; Comisión Europea, 1997; 
Lapavitsas y Noguchi, 2005; Stiglitz y Charlton, 2006; Wade, 2011; Bruszt y McDermott, 2014).

Lo que caracteriza a la mayor parte de estas formas emergentes de GRD es el uso del poder público articulado a través de organizaciones regionales para crear o mejorar instituciones y políticas que aumenten la capacidad de actores nacionales y locales de captar los beneficios de los mercados globales. Competitividad no es, por tanto, un resultado natural de las ventajas comparativas de ciertas economías y sectores — como es asumido bajo el paradigma del regionalismo abierto-, sino que es el resultado de políticas y programas de desarrollo, de la inversión pública y privada en las capacidades locales, y de la producción de bienes colectivos regionales, tales como infraestructura, programas de salud, programas de formación y educación, políticas de armonización y convergencia de normas y estándares, etc. (Rodrik et al., 2004; Estevadeordal et al., 2004; Bruszt y McDermott, 2009).

La figura 1 muestra algunos ejemplos de GRD que se han desarrollado durante este último período. Aunque la gran mayoría de estas iniciativas tiene lugar en lo que se ha tendido a llamar el «Sur Global», no se limitan solo a él. En efecto, los fondos estructurales post-1988 y la Política Europea de Cohesión pueden considerarse también ejemplos de GRD (Delors, 1989; Keating, 2008).

\section{Sudeste Asiático}

En la década de los años noventa surgieron una serie de iniciativas regionales motivadas por el interés de las élites política del Sudeste Asiático de acelerar el proceso de integración y cooperación en el marco de ASEAN. El Programa de la Subregión del Gran Mekong (GMS), el Triángulo de Crecimiento de Indonesia-Malasia-Tailandia (IMT-GT) y el área de Crecimiento del ASEAN Oriental (BIMP-EAGA) surgen como políticas de desarrollo fundamentalmente focalizadas en la conectividad de la infraestructura regional y coordinadas por la Secretaría de ASEAN y por el Banco Asiático de Desarrollo. Se trata de iniciativas que articulan los objetivos de los Gobiernos nacionales y locales, las necesidades de las poblaciones locales y las estrategias de negocios de los agentes privados locales y transnacionales (Bull y Bøås, 2003; Dent y Richter, 2011; Palestini, 2012).

Con posterioridad a la crisis asiática que golpeó fuertemente a las economías de ASEAN mostrando su vulnerabilidad, los líderes de la organización lanzaron la Iniciativa para la Integración de ASEAN (IAI) con el objetivo de coordinar e implementar una cartera de proyectos en las áreas de interconectividad de infraestructura, formación de recursos humanos, TICs 
e integración económica. Luego de una primera evaluación en 2005, el programa se ha expandido en su alcance y en sus recursos a través de la captación y gestión de recursos financieros proveniente mayoritariamente de la región, pero también de oferentes externos a través de cooperación sur-sur triangular (Carpenter et al., 2013).

\section{África subsahariana}

La GRD en África, por su parte, se ha ido coordinando y centralizando de manera creciente a través de la Nueva Asociación para el Desarrollo de África (NEPAD) adoptada por los líderes de la Unión Africana (UA) en 2001, y que opera como un eje para la captación y coordinación de recursos para financiar políticas y programas de desarrollo. Las organizaciones subregionales tales como SADC y ECOWAS, entre otras, también han creado recientemente bancos subregionales de desarrollo y han establecido «vehículos de propósito especial» (special purpose vehicles) con el fin de financiar y coordinar programas fundamentalmente en el área de infraestructura regional, incluyendo la participación de actores privados de dentro y fuera de la región (UNCTAD, 2013; Kararach, 2014).

\section{América Latina}

Pero ha sido América Latina y el Caribe la región en la cual la GRD pareciera haber adquirido particular vigor de la mano del convencimiento, tanto de las élites políticas como de los grupos técnicos operando en organizaciones regionales y multilaterales, acerca de la necesidad de complementar la acción de los mercados con inversión pública y con cooperación interestatal. El distanciamiento del llamado Consenso de Washington subyace a la creación y reorientación de varias organizaciones regionales que hoy existen en América Latina y sus subregiones. El año 2000, los presidentes de los doce países de América del Sur se reunieron por primera vez en la historia y acordaron la creación de la Iniciativa para la Integración de la Infraestructura Regional de Sudamérica (IIRSA), iniciativa que luego pasaría a ser parte de uno de los Consejos Sectoriales de la Unión de Naciones Suramericanas (Unasur). Hoy, Unasur cuenta con doce consejos sectoriales que persiguen la cooperación y la producción de bienes colectivos en áreas tales como integración energética, salud pública, educación, desarrollo social, entre otras (Riggirozzi y Tussie, 2012; Sanahuja, 2012; Palestini y Agostinis, 2015; Bianculli, en prensa).

El año 2004, los líderes del Mercado Común del Sur (Mercosur) adoptaron la creación de un Fondo para la Convergencia Estructural del Mercosur 
(Focem) con el objetivo de reducir las asimetrías entre las economías de los Estados miembros. Aunque la magnitud del fondo es muy reducida, Focem aparece como un equivalente funcional a los fondos estructurales de la UE y a la IAI en ASEAN, iniciativas todas que comparten el objetivo de reducir asimetrías y brechas de desarrollo entre los Estados miembros (De Andrade Correa, 2010; Palestini, 2012).

En 2001, México y los países de América Central introdujeron el Plan Puebla Panamá, más tarde llamado Proyecto Mesoamérica, con una cartera de proyectos en las áreas de infraestructura, desarrollo humano y sustentable, turismo y comercio. Al igual que en el caso de IIRSA, el Proyecto Mesoamérica cuenta con el apoyo y con la coordinación de bancos regionales de desarrollo, incluyendo al CAF y al BCIE.

La importancia de la GRD en América Latina ha sido también impulsada a nivel iberoamericano en el marco del proceso de definición conceptual de la Cooperación para el Desarrollo Sur-Sur y Sur-Sur Triangular (véanse SEGIB, 2014 y 2015). Estos informes reconocen que los mecanismos regionales son ámbitos privilegiados para generar esquemas de cooperación triangular, definidos como aquella modalidad en la que los participantes se distribuyen los roles de primer oferente, segundo oferente y receptor (SEGIB, 2015). De acuerdo a esta definición, una organización regional puede actuar dentro de un esquema de cooperación triangular como segundo oferente, ya sea aportando recursos financieros o brindando capacidades organizativas y de gestión (SEGIB, 2015: 33; Sanahuja et al., 2015).

Para el año 2013, los países iberoamericanos declararon haber participado en 50 programas y 28 proyectos de Cooperación Horizontal Sur-Sur Regional. Más de un tercio de los programas fueron orientados al fortalecimiento de capacidades socio-económicas, y nueve de cada diez programas fueron regulados por organizaciones regionales (SICA, CAN, Unasur y los organismos pertenecientes a la Conferencia Iberoamericana). A nivel de proyectos, la mitad fueron regulados por organizaciones regionales con un predominio de Mercosur y de la Alianza del Pacífico con cuatro proyectos respectivamente. Las organizaciones regionales tuvieron participación ya sea en la identificación, la negociación, la implementación y/o la evaluación de los proyectos (SEGIB, 2015).

Estos programas y proyectos constituyen un indicador de la institucionalización de la GRD en el espacio de América Latina y el Caribe. Sin embargo, ¿quiénes son los actores que gestan y participan en estas iniciativas? ¿Cuáles son los factores que explican que estas iniciativas logren pasar de los dichos a los hechos implementando bienes colectivos? En la segunda parte de este artículo se analizará en detalle una iniciativa específica de GRD, con el fin de responder estas preguntas. 


\section{LA GOBERNANZA REGIONAL DEL DESARROLLO EN ACCIÓN: LA COOPERACIÓN SECTORIAL EN INFRAESTRUCTURA EN AMÉRICA DEL SUR (2000-2015)}

En esta segunda parte se analizará la cooperación regional en infraestructura en América del Sur, como un caso de GRD. La cooperación sectorial en infraestructura se convirtió en un objetivo prioritario para los gobiernos de la región luego de la Primera Cumbre de Presidentes en Brasilia en septiembre de 2000, y se institucionalizó en la Iniciativa para la Integración de la Infraestructura Regional de Sudamérica (IIRSA) con el mandato de ampliar y modernizar la infraestructura de transporte, energía y telecomunicaciones de la región $^{2}$. Desde 2010, IIRSA es parte del Consejo de Infraestructura y Planificación de Unasur (Cosiplan), y para 2014 presentaba una cartera de 560 proyectos, con 107 ya implementados, como se puede apreciar en la tabla 1.

Tabla 1. Número de proyectos por área y fase de implementación (2014)

\begin{tabular}{lcc}
\hline Fase & Transporte & Energía \\
\hline Implementado & 86 & 21 \\
\hline En ejecución & 154 & 12 \\
\hline Preejecución & 266 & 21 \\
\hline Total & $\mathbf{5 1 6}$ & $\mathbf{5 4}$ \\
\hline
\end{tabular}

Fuente: elaboración propia a partir del Sistema de Información IIRSA-Cosiplan.

El hecho de que sea una iniciativa de relativa antigüedad (15 años), que presenta además un significativo, aunque variable, nivel de implementación de bienes colectivos regionales (más alto en el área de transporte que en el área de energía), hace de la cooperación sectorial en infraestructura un área de interés académico para comprender de qué modo actores estatales y no estatales se coordinan en un proceso de Gobernanza Regional del Desarrollo.

\section{MARCO CONCEPTUAL Y METODOLÓGICO}

El objetivo de este estudio de casos es identificar los factores y mecanismos que permiten implementar bienes colectivos regionales, tales como

2 Declaración de Brasilia 2000, párrafo 39. 
interconexiones de transporte (puentes, carreteras, puertos e hidrovías), interconexiones energéticas (refinerías, gasoductos, oleoductos y plantas eléctricas) y armonización o convergencia de regulaciones nacionales (peajes transfronterizos, impuestos de embarque y desembarque, normativa de transporte y distribución de energía). En términos metodológicos, la «implementación de bienes colectivos regionales» constituye, pues, la variable dependiente del estudio.

¿Cómo explicar la implementación de bienes colectivos regionales? Desde un punto de vista analítico, el estudio se ciñe a la definición de Gobernanza Regional del Desarrollo brindada en la primera parte del artículo (véase Bruszt y Palestini, 2016). Esta definición requiere incluir en el análisis factores que se ubican al nivel de las relaciones entre Gobiernos (perspectiva intergubernamental), pero también entre Gobiernos y actores no estatales y multilaterales (perspectiva transnacional).

Cabe destacar que en América Latina en general, y en Sudamérica en particular, los estudios sobre regionalismo han tendido a asumir una perspectiva intergubernamental. Autores tales como Andrés Malamud (2003, 2005) y Olivier Dabène (2012) sostienen que el hecho de que los Estados sudamericanos presenten regímenes políticos presidencialistas implica que sean los Ejecutivos y, en definitiva, los presidentes, los principales, si no los únicos, responsables de la política exterior en general y de la cooperación regional en particular; diplomacia presidencial e interpresidencialismo son el equivalente de lo que en Europa ha sido el supranacionalismo (véanse también Malamud, 2008; Gardini y Lambert, 2011; Neto, 2011).

Este estudio concuerda con estos autores acerca de que una perspectiva intergubernamental es necesaria para estudiar la cooperación regional. Sin embargo, se sostiene al mismo tiempo que dicha perspectiva no es suficiente. Las decisiones tomadas a nivel intergubernamental y expresadas en declaraciones o formalizadas en tratados son el insumo básico para que la cooperación regional tenga lugar; empero, para que dicho insumo sea implementado en bienes colectivos regionales concretos se necesita de la agencia de otros actores, locales, multilaterales y transnacionales. Organizaciones multilaterales, en particular, escapan al control de un único gobierno nacional, por lo que definen objetivos y visiones con relativa autonomía. Sin embargo, su capacidad de agencia está ciertamente limitada por la soberanía nacional de los Estados. Esta segunda propiedad diferencia a una organización multilateral de una organización supranacional, categoría a la que corresponden, por ejemplo, los órganos que componen la Unión Europea.

Para realizar el estudio de casos se ha utilizado la metodología de process tracing analysis, un método elaborado en ciencias políticas y que tiene el objetivo de identificar paso a paso los factores que explican — a lo largo de una trayectoria temporal - las variaciones en una variable dependiente (Venesson, 
2008; Bennett y Checkel, 2015). A través de esta metodología es posible reconstruir la interacción entre los factores, es decir el mecanismo causal que explica un determinado efecto (Héritier, 2008). El análisis de process tracing se efectuó a lo largo del periodo 2000-2015, rastreando las variaciones en la implementación de bienes colectivos regionales. La línea temporal se aprecia en la figura 2, mostrando las principales cumbres presidenciales (bajo la línea) y las principales instituciones creadas (sobre la línea).

\section{Figura 2. Linea temporal}

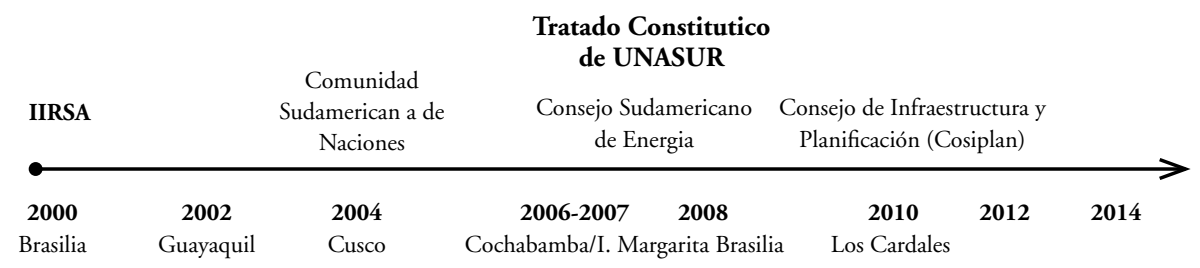

Las fuentes utilizadas fueron textuales y orales. El cuerpo textual analizado se compone de 120 textos correspondientes a las declaraciones presidenciales resultantes de todas las cumbres de presidentes sudamericanos del período bajo estudio, y algunas cumbres ministeriales, además de actas de reuniones y grupos de trabajo técnicos, y documentos e informes técnicos publicados y no publicados. Las fuentes orales fueron recolectadas a través de 42 entrevistas semiestructuradas efectuadas con miembros de los gobiernos de los Estados miembros de Unasur encargados de la política externa, y tomadores de decisiones vinculados a temas de infraestructura y energía a nivel nacional como también regional/internacional. La recolección de documentos y las entrevistas fueron realizadas en dos períodos de trabajo de campo en Sudamérica entre septiembre y diciembre de 2012, y entre octubre y enero de 2013. La lista de entrevistas puede consultarse en el anexo del artículo.

\section{PRESENTACIÓN DE LOS HALLAZGOS}

El análisis de process tracing permitió identificar cuatro factores que explican la implementación de bienes colectivos regionales en el marco de la cooperación regional en infraestructura. A continuación se presentarán estos factores en dos subsecciones. En la primera se describirá cada factor por separado, para luego, en la segunda subsección presentar la manera en que ellos interactúan, identificando el mecanismo causal que explica la implementación de bienes colectivos regionales. 


\section{Mecanismos que explican la implementación}

a) Consenso intergubernamental

El análisis mostró la existencia de un consenso entre los gobiernos de la región acerca de que la cooperación en el área de infraestructura representaba una situación ganadora para todas las partes. El análisis de las sucesivas declaraciones presidenciales mostró además que dicho consenso se mantuvo, al menos para la cooperación en infraestructura de transporte, a lo largo de todo el período estudiado ${ }^{3}$.

Dicho consenso intergubernamental se forjó durante las Cumbres Presidenciales de 2000 en Brasilia y de 2002 en Guayaquil. Aunque las agendas de ambas cumbres eran más amplias incluyendo un número importante de áreas y líneas de cooperación, la única área que fue institucionalizada en una iniciativa concreta fue la integración de la infraestructura regional. Hay tres razones que explican este consenso: primero, la situación precaria de la infraestructura en general empeorada por un marcado descenso en la década de los noventa de la inversión pública, no morigerado por el tibio aumento de la inversión privada. En el quinquenio 1996-2001, la inversión pública se redujo en dos tercios y la inversión privada solo aumentó en uno respecto al quinquenio 1980-1985 (OCDE, 2012). Segundo, la existencia de una propuesta concreta elaborada por el gobierno brasileño y con el soporte y aval técnico de los bancos regionales de desarrollo y de la CEPAL. Y tercero, cada uno de los Gobiernos pudo identificar de manera clara los beneficios asociados con un programa de infraestructura regional, como se aprecia en la tabla 2.

Tabla 2. Intensidad de las preferencias respecto a la cooperación en infraestructura antes de la Cumbre de Brasilia (2000)

\begin{tabular}{lcc}
\hline Gobierno nacional & $\begin{array}{c}\text { Preferencias en } \\
\text { infraestructura de transporte }\end{array}$ & $\begin{array}{c}\text { Preferencias en } \\
\text { infraestructura de energía }\end{array}$ \\
\hline Brasil & $\begin{array}{l}\text { Alta. Reforzar lazos } \\
\text { regionales, mientras } \\
\text { la agenda comercial se } \\
\text { encontraba bloqueada. }\end{array}$ & $\begin{array}{c}\text { Alta. Reforzar lazos } \\
\text { regionales, mientras } \\
\text { la agenda comercial se } \\
\text { encontraba bloqueada. }\end{array}$ \\
\hline
\end{tabular}

3 El caso de la cooperación en energía merece un comentario aparte. En efecto, en el caso energético el consenso intergubernamental sufrió un serio quiebre a mediados de la década de los 2000 (véanse Palestini y Agostinis, 2015; Palestini, 2016). 
$\ldots / \ldots$

\begin{tabular}{|c|c|c|}
\hline Gobierno nacional & $\begin{array}{l}\text { Preferencias en } \\
\text { infraestructura de transporte }\end{array}$ & $\begin{array}{c}\text { Preferencias en } \\
\text { infraestructura de energía }\end{array}$ \\
\hline $\begin{array}{l}\text { MERCOSUR } \\
\text { (Argentina, Paraguay } \\
\text { y Uruguay) }\end{array}$ & $\begin{array}{c}\text { Alta. Reducir asimetrías } \\
\text { con Brasil, principalmente } \\
\text { en materia de inversión en } \\
\text { infraestructura. }\end{array}$ & $\begin{array}{l}\text { Alta. Encontrar mercados } \\
\text { para los excedentes energéticos } \\
\text { (Paraguay); mejorar la } \\
\text { seguridad energética } \\
\text { (Argentina y Uruguay). }\end{array}$ \\
\hline Chile & $\begin{array}{c}\text { Alta. Estimular las industrias } \\
\text { de embarco y desembarco } \\
\text { en los puertos del litoral } \\
\text { norte. }\end{array}$ & $\begin{array}{c}\text { Alta. Mejorar la seguridad } \\
\text { energética. }\end{array}$ \\
\hline$\overline{\text { Perú }}$ & $\begin{array}{l}\text { Alta. Estimular las industrias } \\
\text { de embarco y desembarco } \\
\text { en los puertos del Pacífico; } \\
\text { aumentar la conectividad de } \\
\text { transporte con Brasil. }\end{array}$ & $\begin{array}{l}\text { Alta. Encontrar mercados } \\
\text { para los excedentes } \\
\text { energéticos. }\end{array}$ \\
\hline Bolivia & $\begin{array}{l}\text { Alta. Aliviar los déficits } \\
\text { en infraestructura y } \\
\text { ganar acceso a la ayuda al } \\
\text { desarrollo de Brasil. }\end{array}$ & $\begin{array}{l}\text { Alta. Encontrar mercados } \\
\text { para los excedentes } \\
\text { energéticos. }\end{array}$ \\
\hline Ecuador & $\begin{array}{l}\text { Alta. Aliviar los déficits } \\
\text { en infraestructura y } \\
\text { ganar acceso a la ayuda al } \\
\text { desarrollo de Brasil. }\end{array}$ & $\begin{array}{l}\text { Alta. Diversificar la matriz } \\
\text { energética. }\end{array}$ \\
\hline Colombia & $\begin{array}{l}\text { Alta. Aliviar los déficits } \\
\text { en infraestructura y } \\
\text { ganar acceso a la ayuda al } \\
\text { desarrollo de Brasil. }\end{array}$ & $\begin{array}{l}\text { Alta. Diversificar la matriz } \\
\text { energética. }\end{array}$ \\
\hline Venezuela & $\begin{array}{l}\text { Alta. Aliviar los déficits en } \\
\text { infraestructura; aumentar la } \\
\text { conectividad de transporte } \\
\text { con Brasil. }\end{array}$ & $\begin{array}{l}\text { Alta. Encontrar mercados } \\
\text { para los excedentes } \\
\text { energéticos; mejorar la } \\
\text { capacidad técnica para la } \\
\text { explotación de yacimientos de } \\
\text { crudo pesado y súper pesado. }\end{array}$ \\
\hline Surinam-Guyana & $\begin{array}{l}\text { Alta. Aliviar los déficits en } \\
\text { infraestructura; aumentar la } \\
\text { conectividad de transporte } \\
\text { con Brasil y ganar acceso a la } \\
\text { ayuda al desarrollo de Brasil. }\end{array}$ & $\begin{array}{c}\text { Alta. Mejorar la seguridad } \\
\text { energética. }\end{array}$ \\
\hline
\end{tabular}

Fuente: elaboración propia basada en entrevistas y análisis textual. 
Este consenso se mantuvo a lo largo de la década a pesar de los cambios de Gobiernos en muchos Estados sudamericanos. En efecto, en la Cumbre de Cochabamba de 2006 los Gobiernos de Venezuela y de Bolivia presentaron observaciones críticas a la manera en que IIRSA había sido concebida y al modo en que se estaba conduciendo por parte de los bancos regionales. Las críticas se concentraron fundamentalmente en la supuesta primacía de criterios financieros sobre criterios sociales para componer la cartera de proyectos, y la amenaza que algunos de los proyectos representaban para el medio ambiente y para comunidades campesinas y de pueblos originarios. Las críticas se procesaron dentro del contexto intergubernamental y motivaron reformas en la organización de IIRSA, sin por ello impedir el funcionamiento de la misma, que fue fuertemente respaldada por el resto de los Gobiernos de la región.

b) Relaciones estratégicas con organizaciones multilaterales

El análisis mostró también que, desde su fundación, IIRSA contó con el rol protagónico de organizaciones multilaterales. En efecto, IIRSA nació de una relación de colaboración entre funcionarios del Ministerio de Planificación de Brasil que habían implementado dos complejos programas de integración física en el territorio federal brasilero (Brasil em Ação y Avança Brasil) durante el mandato del presidente Fernando Henrique Cardoso, dos bancos multilaterales de desarrollo (BID y CAF) y una organización regional, CEPAL. Un estudio comisionado por el presidente Cardoso al BID y a CEPAL, «Un Nuevo Impulso para el Desarrollo de la Integración Regional de América del Sur», se transformaría en la hoja de ruta de IIRSA durante su primera década de funcionamiento, dotándola de las directrices en materia de planificación y logística territorial.

A través de la Declaración de Brasilia, los Gobiernos sudamericanos delegaron al BID, al CAF y a Fonplata la conducción y la organización de IIRSA ${ }^{4}$. El Instituto para la Integración de América Latina (INTAL) se transformó en la secretaría técnica de IIRSA que, por primera vez en la historia, hizo posible la cooperación entre los 12 ministerios nacionales responsables de la planificación territorial, las obras públicas y la política energética. En efecto, antes de IIRSA estas agencias operaban en desconexión unas de otras, por lo que los planes nacionales eran concebidos de manera aislada e independiente, sin tomar en cuenta la dimensión regional y transnacional del territorio y con el resultado de que, por ejemplo, una carretera nacional arribaba al momento de cruzar un

4 En conjunto, los tres bancos integraron el Comité de Coordinación Técnica (CCT) de IIRSA. Fonplata es el Fondo para el Desarrollo de la Cuenca del Plata. 
borde nacional a un punto ciego imposibilitando intercambios comerciales y reduciendo la interconexión de las comunidades transfronterizas aledañas.

Como fruto de la cooperación entre funcionarios de los ministerios nacionales y funcionarios de los bancos regionales se adoptó el concepto de «Eje de Integración y Desarrollo» como herramienta conceptual básica para diseñar la primera cartera de proyectos consensuados entre los países de la región. El concepto de «Eje» fue definido como una franja transnacional de territorio que comprende una cierta dotación de recursos naturales, comunidades humanas, áreas productivas y servicios logísticos, y que está articulada a través de redes de transporte, energía y comunicación que facilita el flujo de personas, bienes, servicios e información entre el territorio y desde el territorio hacia el resto del globo (Banco Interamericano de Desarrollo, 2000). La Cartera de IIRSA se compuso de diez Ejes, que se han mantenido con el paso de IIRSA a Cosiplan, añadiendo un Eje adicional, el Amazónico.

Con la creación de Unasur y con la integración de IIRSA al Consejo de Infraestructura y Planificación de Unasur (Cosiplan), las agencias nacionales y sus coordinadores han asumido un rol más protagónico. Sin embargo, como los propios coordinadores nacionales de Cosiplan reconocen, el rol de los bancos regionales de desarrollo continúa siendo fundamental para llevar a cabo las reuniones técnicas, contar con apoyo para el uso e implementación de las numerosas metodologías que se crearon en el seno de IIRSA, y para mejorar la presentación financiera de los proyectos de la cartera IIRSA-Cosiplan a la hora de buscar financiación en los mercados de capitales.

\section{c) Movilización de actores privados}

Las teorías de la integración regional, la gran mayoría concebida e inspirada por el caso europeo, atribuyen una gran importancia a los actores privados (compañías, asociaciones empresariales, etc.) a la hora de explicar el éxito o fracaso de las experiencias de integración regional (véanse, por ejemplo, Mansfield y Milner, 1997; Mattli, 1999). En América Latina y en América del Sur, en particular, el rol de los privados ha sido mucho menor que en Europa a la hora de explicar los procesos de regionalismo e integración regional. La explicación radica en el hecho de que el mercado regional sudamericano - es decir los intercambios económicos y financieros entre las economías de la región- continúa siendo relativamente pequeño y fragmentado si se compara con el mercado europeo, norteamericano o del sudeste asiático. Es cierto que el mercado regional de manufacturas es relativamente importante en América del Sur; sin embargo, si uno compara el comercio intrarregional de bienes intermedios (una medida convencional de integración productiva) vemos que Sudamérica (14\% del total de exportaciones) figura bastante por debajo de la Unión 
Europea (39\%), de América Central y México (31\%) y del Sudeste Asiático $(30 \%)$. En el léxico de la ciencia política, la «interdependencia económica» en Sudamérica es baja en términos comparativos (CEPAL, 2014).

Esto, sin embargo, no invalida el hecho de que la inclusión de los actores privados - domésticos y transnacionales - es fundamental para poder pasar de los «dichos» a los «hechos» en materia de implementación de bienes colectivos regionales. Pero dicha inclusión no sucede de manera espontánea, sino que requiere de una acción proactiva de parte de gobiernos, organizaciones regionales y multilaterales que permita alinear las estrategias corporativas de las empresas con los proyectos de integración regional.

El análisis de la cooperación regional en infraestructura en el marco de IIRSA, y luego Cosiplan, muestra una incipiente capacidad de asociar privados en la implementación de bienes colectivos regionales.

Tabla 3. Cartera de proyectos de transporte según tipo de financiamiento

\begin{tabular}{lcc}
\hline Tipo de financiamiento & Número de proyectos & $\begin{array}{c}\text { Inversión estimada } \\
\text { (dólares) }\end{array}$ \\
\hline Público & 399 & 68.887 .700 .106 \\
\hline Privado & 70 & 28.883 .750 .990 \\
\hline PPP (público-privado) & 35 & 10.669 .209 .788 \\
\hline Total & $\mathbf{5 0 4}$ & $\mathbf{1 0 8 . 4 4 0 . 6 6 0 . 8 8 4}$ \\
\hline
\end{tabular}

Fuente: elaboración propia, a partir de Sistema de Información IIRSA-Cosiplan.

La tabla 3 muestra la cartera de proyectos de transporte de IIRSA-Cosiplan. Aunque la gran mayoría de los proyectos cuenta con un esquema de financiamiento público (399), 105 proyectos cuentan con financiamiento privado y, de ellos, 35 constituyen iniciativas público-privadas. Proyectos emblemáticos como las carreteras IIRSA-Sur e IIRSA-Norte, que forman parte del Eje Inter-Oceánico y del Eje Perú-Brasil-Paraguay, fueron financiadas a través de una modalidad público-privada sobre la base de concesiones otorgadas por el Gobierno peruano a una compañía de construcción brasileña 5 .

5 En febrero de 2017 la Fiscalía del Perú inició una investigación por supuesta colusión entre la compañía constructora brasileña Oderbrecht y la Agencia de Promoción de la Inversión Privada, organismo perteneciente al Estado peruano. La colusión habría ocurrido durante la firma de los contratos para la construcción de IIRSA-Sur, lo que siembra un manto de escepticismo respecto a las asociaciones público-privadas en la región. 
d) Ingeniería financiera

Finalmente, el análisis ha mostrado la importancia de contar con mecanismos financieros diversificados para poder implementar bienes colectivos regionales, en especial cuando se trata de inversiones de largo plazo, como es el caso de los proyectos de infraestructura. En efecto, los proyectos de infraestructura regional enfrentan una serie de dificultades adicionales para su financiamiento. En primer lugar, se trata de proyectos muchas veces binacionales o incluso multinacionales, lo cual requiere de un marco institucional que facilite y provea seguridad jurídica a la implementación del proyecto. En segundo lugar, se trata de proyectos de integración que por su locación en áreas lejanas a los centros urbanos presentan un bajo retorno de la inversión en el corto plazo, y una baja visibilidad, lo que desincentiva a los actores privados y también a los Gobiernos a invertir en dichos proyectos.

Así, por ejemplo, las entrevistas con funcionarios, tanto de los Gobiernos como de los bancos regionales, reflejaron que los Gobiernos — particularmente las agencias encargadas del presupuesto, como los ministerios de Hacienda o de Economía - tienden a priorizar proyectos de infraestructura domésticos de mayor visibilidad (un hospital o una carretera urbana) por encima de un proyecto de integración regional cuyos beneficios inmediatos tienden a ser más limitados en términos relativos. Una adecuada y creativa ingeniería financiera es necesaria, por tanto, para evitar que estos proyectos con beneficios a medio y largo plazo queden entrampados en la etapa de preejecución.

El análisis mostró que IIRSA-Cosiplan hace uso de una arquitectura financiera creativa que, sin embargo, requiere ser robustecida para acelerar el nivel de implementación. La tabla 3 mostraba que la mayoría de los proyectos de transporte cuentan con financiamiento público. Sin embargo, cuando esta categoría "pública» se descompone, obtenemos una figura más compleja, como se aprecia en la tabla 4.

Tabla 4. Fuente de financiamiento público de la cartera de proyectos de transporte

\begin{tabular}{lcc}
\hline Fuente de financiamiento & Número de proyectos & $\begin{array}{c}\text { Inversión estimada } \\
\text { (dólares de EE.UU.) }\end{array}$ \\
\hline BID & 34 & 8.631 .697 .490 \\
\hline CAF & 24 & 3.768 .649 .972 \\
\hline Fonplata & 6 & 524.412 .784 \\
\hline Focem & 7 & 763.510 .000 \\
\hline BNDES & 3 & 418.600 .000 \\
\hline Total & $\mathbf{7 3}$ & $\mathbf{1 4 . 1 0 6 . 8 7 0 . 2 4 6}$ \\
\hline
\end{tabular}

Fuente: elaboración propia, Sistema de Información IIRSA-Cosiplan. 
Se observa que los bancos regionales — principalmente BID y CAF- participan en el financiamiento de proyectos IIRSA-Cosiplan a través de préstamos a los Gobiernos. También Fonplata y el Fondo para la Convergencia Estructural del Mercosur (Focem) participan en la financiación de proyectos de infraestructura de transporte. Como se ha mencionado en la primera parte del artículo, el Focem es un instrumento innovador que funciona como fondo perdido, sin condicionalidades, y bajo un principio redistributivo donde Brasil, seguido por Argentina, son los principales contribuyentes, y Paraguay y Uruguay, los principales beneficiarios. Con la adhesión de Venezuela y Bolivia al Mercosur, el Focem adquirirá una nueva dimensión y cubrirá a la mitad de los países de la región. El Banco del Sur, cuya acta fundacional fue firmada en el 2007 por seis de los doce países de la región, podría también formar parte de la arquitectura financiera de los proyectos IIRSA-Cosiplan; sin embargo, su puesta en marcha ha enfrentado una serie de dificultades políticas y técnicas. El Grupo sobre mecanismos financieros y de garantías de Cosiplan también ha iniciado conversaciones con instituciones financieras extrarregionales (el Banco de Desarrollo Chino y el Banco de Desarrollo de los BRICS) para explorar una posible participación en la financiación de proyectos de infraestructura.

La tabla 4 muestra además la participación del Banco Nacional de Desarrollo Económico y Social de Brasil (BNDES) en la financiación de tres proyectos de transporte: dos carreteras en Bolivia y el puente Acre entre Brasil y Perú. No obstante, la participación del BNDES en la financiación de infraestructura en Sudamérica va más allá de la Cartera IIRSA-Cosiplan. El BNDES financió 17 proyectos de infraestructura entre 2005 y 2010 implementados por empresas de capital brasileño y haciendo uso de su modalidad de asistencia financiera Exim así como del Convenio sobre Créditos y Pagos Recíprocos establecido por la ALADI en 1983, y que actúa como una garantía de operaciones financieras en la región a través de un sistema multilateralizado de líneas de créditos. Es un punto a discutir, no obstante, si los proyectos financiados por el BNDES fuera de la Cartera IIRSA-Cosiplan corresponden a «bienes colectivos regionales»o son más bien proyectos de alcance exclusivamente nacional. La actual crisis económica y política que afecta a Brasil añade dudas adicionales acerca del rol que el BNDES jugará en iniciativas de GRD en el futuro en Sudamérica.

\section{Interacción entre los factores}

La metodología de process tracing no solo permite identificar los factores que explican una determinada variable dependiente, sino que además posibilita entender cómo dichos factores interactúan, es decir, permite reconstruir el «mecanismo causal» (Héritier, 2008). La figura 3 ilustra dicho mecanismo causal para el caso de la cooperación regional en infraestructura. 
Figura 3. Mecanismo causal

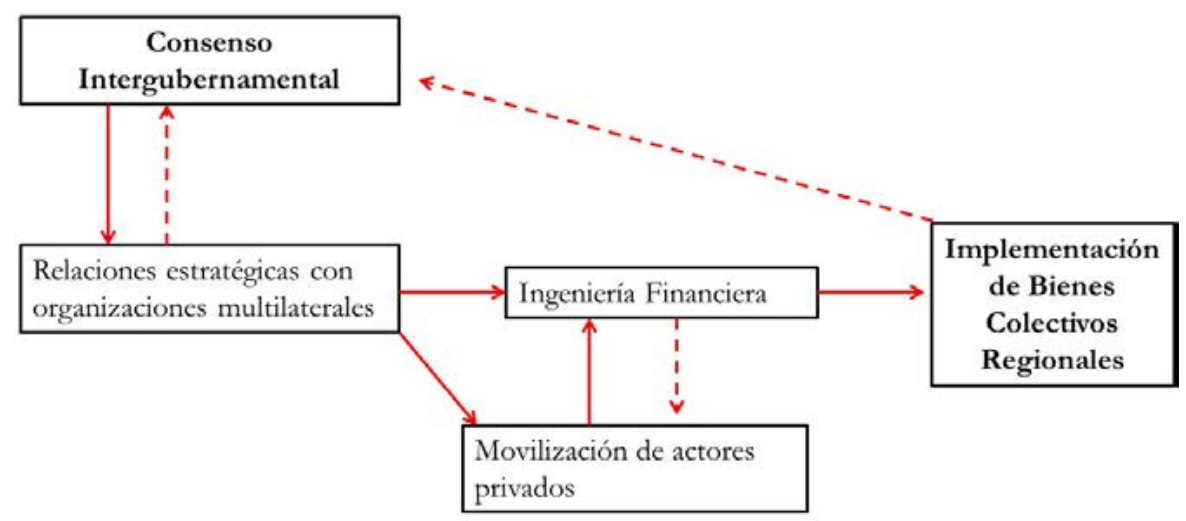

Fuente: elaboración propia.

El consenso intergubernamental es la condición necesaria (sine qua non) para que exista cooperación y coordinación de políticas y, por ende, implementación de bienes colectivos regionales. El consenso entre los Ejecutivos nacionales provee dos ingredientes fundamentales para la cooperación: legitimidad y eficacia. Cuando el consenso intergubernamental flaquea, la cooperación regional se convierte en flanco de críticas, ya sea por falta de legitimidad ante el público o por falta de eficacia en la implementación. El análisis efectuado mostró que esto sucedió para el caso de la cooperación sectorial en energía, lo que explica la baja tasa de implementación de proyectos de integración energética cuando se compara con la implementación de proyectos en transporte.

En efecto, durante las cumbres de Brasilia (2005), Cochabamba (2006) y la Cumbre Energética de Isla Margarita (2007), los Gobiernos nacionales no lograron hacer converger sus preferencias acerca de qué tipo de integración querían llevar a cabo y de qué manera querían hacerlo. Mientras algunos países abogaron por IIRSA como la plataforma idónea, otros optaron por nuevas iniciativas englobadas en el marco de PETROAMÉRICA. Una serie de tensiones intergubernamentales en materia energética coadyuvaron a que el consenso se rompiera y la cooperación sectorial quedase entrampada, lo que aún se observa al día de hoy en el seno del Consejo Energético de Unasur y de las discusiones para definir un Tratado Energético Sudamericano (para el caso de la cooperación sectorial en energía, véanse Palestini y Agostinis, 2015; Palestini, 2016).

El consenso acerca de los beneficios mutuos en un área de cooperación es por tanto una conditio sine qua non; sin embargo, no es condición suficiente para alcanzar la implementación. Como se observa en la figura 3, la alianza estratégica con organizaciones multilaterales actúa como una suerte de bisagra 
entre los distintos factores causales identificados. La acción de los bancos regionales de desarrollo permitió coordinar y generar confianza entre las autoridades nacionales encargadas de planificar la infraestructura rompiendo con una historia de aislamiento y mutua desinformación, permitió asimismo articular asociaciones público-privadas, y funcionó además como eje para montar una ingeniería financiera que fuera capaz de trasladar los proyectos desde el papel a la realidad.

La flecha intermitente hacia "consenso intergubernamental» busca ilustrar que la asociación con los bancos regionales permitió asimismo afianzar el propio consenso intergubernamental. En el año 2000 los Gobiernos estuvieron dispuestos a emprender la aventura de IIRSA precisamente porque la presencia de los bancos regionales y, en sus inicios, CEPAL, daba garantías de que la iniciativa iba a contar con las capacidades organizativas y financieras. Otras organizaciones multilaterales y actores transnacionales pueden también cumplir el rol de «bisagras» para facilitar la implementación. En este sentido, la Secretaría General de Unasur, que desde el 2014 ha iniciado un proceso de construcción de capacidades a través de la creación de direcciones que apoyen y supervisen los consejos sectoriales, podrá cumplir un rol cada vez más importante en la coordinación de iniciativas de GRD.

La presencia de actores privados y de una ingeniería financiera son los factores más inmediatos que explican la implementación. La relación entre ambos es recíproca: modalidades creativas de financiación ayudan a atraer la participación privada; los privados, a su vez, contribuyen a diversificar las opciones de financiamiento. Finalmente, la flecha intermitente entre «implementación» y «consenso intergubernamental» simboliza el mecanismo de retroalimentación (feedback) fundamental: en la medida en que las iniciativas de cooperación son capaces de implementar bienes regionales, el consenso intergubernamental se afianza y el resto de los engranajes de la cooperación se consolida. Este feedback es esencial, pues los regímenes regionales intergubernamentales son por definición frágiles y sensibles a los cambios de Gobierno y de coaliciones (Strange, 1983). La única manera de que una iniciativa de gobernanza regional del desarrollo se mantenga en el tiempo y se institucionalice recae en última instancia en su capacidad de presentar resultados, lo que en ciencias políticas se ha denominado precisamente «legitimidad de resultado».

\section{CONCLUSIONES: DESAFÍOS PARA LA GOBERNANZA REGIONAL DEL DESARROLLO EN UN CONTEXTO GLOBAL INCIERTO}

Este artículo ha explorado la relación entre regionalismo y desarrollo a través del concepto de Gobernanza Regional de Desarrollo (GRD). La primera parte del artículo ha ilustrado este concepto a través de la experiencia histórica y 
comparada. Se ha argumentado que el paradigma del regionalismo abierto - a nivel regional — y del ajuste estructural —a nivel doméstico — contribuyeron a disociar las políticas regionales de las políticas de desarrollo, reduciendo las primeras a la acción automática de los mercados, y confinando las segundas a la superación de la extrema pobreza con fines humanitarios. Sin embargo, desde 1990 , y con particular vigor a partir del nuevo milenio, nuevas iniciativas surgidas desde los propios proyectos regionales están combinando cooperación regional con políticas públicas de desarrollo para producir bienes colectivos en diversos sectores con beneficios concretos para las poblaciones.

La segunda parte del artículo ha profundizado en un caso específico de GRD en América del Sur. Se ha mostrado cómo la existencia de un consenso intergubernamental y la alianza estratégica con organizaciones multilaterales ha permitido generar una incipiente participación privada y una creativa ingeniería financiera que han resultado en la implementación de infraestructura regional en el área de transporte y, en un grado menor, en el área energética. De este modo, la experiencia IIRSA-Cosiplan se puede considerar un caso relativamente exitoso de GRD y de lo que los países en el contexto de la cooperación iberoamericana han venido a llamar la cooperación horizontal sursur regional (SEGIB, 2015).

El hecho de ser una experiencia exitosa no quiere decir, empero, que la cooperación sectorial en América del Sur esté exenta de desafíos que enfrentar para su consolidación futura, algunos de los cuales son generalizables para otros casos de GRD dentro y fuera de la región.

El primer desafío es de orden sistémico y de relación con la coyuntura de la economía política global. Luego de la Gran Recesión (2008) y de la crisis de la eurozona (2010), el contexto económico global se caracteriza por una marcada desaceleración del crecimiento y desequilibrios macroeconómicos (desequilibrio de cuentas corrientes, exceso de liquidez y baja demanda efectiva, y un marcado desequilibrio en los términos del intercambio). La desaceleración de la economía china y la adopción por parte de Pekín de una estrategia de sustitución de importaciones influyen en que América Latina, y especialmente América del Sur y el Caribe, enfrenten hoy su peor desempeño exportador en las últimas ocho décadas. Hoy los países de la región presentan una estructura productiva no muy diferente a la que tenían en la década de los años cincuenta, durante los orígenes del regionalismo desarrollista, es decir, una matriz exportadora no diversificada y primarizada, y una matriz importadora muy diversificada y dependiente de bienes de capital y tecnología (CEPAL, 2015). En este contexto negativo, la cooperación sur-sur y, particularmente, la GRD aparecen como estrategias no solo necesarias, sino urgentes. Bienes colectivos regionales tales como infraestructura en transporte (pero también en energía y telecomunicaciones), un sistema de educación y formación regional, políticas 
industriales regionales, etc., son necesarios para poder generar los encadenamientos productivos y mercados regionales que permitirán realizar el objetivo de desarrollo de largo plazo: un crecimiento endógeno, menos dependiente y vulnerable a los choques externos. Este artículo ha mostrado que iniciativas similares a IIRSA-Cosiplan se están adoptando en África (en el marco de NEPAD) y en el Sudeste Asiático (IAI); América Latina puede y debe aprender de las experiencias en estas y otras regiones.

Un segundo desafío consiste en preguntarse cuán «buenos» y cuán «colectivos» son los «bienes colectivos regionales» que se busca implementar. Ciertos bienes colectivos (carreteras internacionales, plantas energéticas, represas) pueden tener efectos distributivos de diverso signo según el sector de la población que se mire. IIRSA, por ejemplo, enfrentó durante sus primeros años de funcionamiento críticas y cuestionamientos por parte de movimientos sociales ambientalistas y defensores de los pueblos originarios. Las iniciativas de GRD requieren por tanto ser inclusivas e involucrar en su diseño a todos los potenciales interesados. En muchas regiones, los ciudadanos desconocen la proveniencia de ciertos bienes colectivos, incluso de aquellos que pueden tener un impacto directo en sus vidas. Pocos ciudadanos peruanos o brasileños saben, por ejemplo, que la nueva carretera que atraviesa sus poblados y los conecta fue ejecutada gracias a una iniciativa regional y que involucró a más de un Gobierno de la región. Incluso en el contexto de la Unión Europea - la organización regional que más se acerca a un sistema político con formas más sofisticas de accountability - los tomadores de decisiones se lamentan de la falta de debate en el Parlamento Europeo acerca de los resultados y efectos de los programas implementados por la Política de Cohesión. Una GRD inclusiva y con mayor visibilidad de cara a los ciudadanos contribuirá al arraigamiento de estas iniciativas y al sentido de pertenencia... y en el largo plazo a la «identidad regional» de los ciudadanos.

Finalmente, para ser efectiva, la GRD requiere de capacidades regionales más robustas. Iniciativas y políticas tales como las que los consejos sectoriales y grupos de trabajo de Unasur, Mercosur y CAN buscan implementar requieren de un apoyo y de un seguimiento técnico profesional y capacitado. América Latina cuenta con un número importante de organizaciones regionales y multilaterales, algunas de ellas de conocimiento experto que pueden contribuir, en coordinación con las secretarías generales, al diseño y seguimiento de las políticas públicas regionales. La cooperación entre la Secretaría General de Unasur y organizaciones tales como CEPAL y OLADE (Organización Latinoamericana de Energía) va en esta línea. Así mismo, parte de la cooperación internacional para el desarrollo podría ser canalizada para el fortalecimiento institucional de las secretarías generales, de los fondos regionales y de los institutos regionales existentes. 


\section{Bibliografía}

Babb, S. (2009). Behind the Development Banks. Chicago: University of Chicago Press. Disponible en: https://doi.org/10.7208/chicago/9780226033679.001.0001.

Balassa, B. (1962). The Theory of Economic Integration. London: Allen and Unwin.

Banco Interamericano de Desarrollo (2000). A new push for regional infrastructure development in South America. Washington: BID.

Banco Mundial (1994). The World Bank Annual Report. Washington: Banco Mundial.

Bennett, A. y Checkel, J. T. (2015). Process tracing: From metaphor to analytical tool. Cambridge: Cambridge University Press.

Bhagwati, J. (1993). Regionalism and multilateralism: An overview. En J. De Melo y A. Panagariya (eds.). New Dimensions in regional integration (pp. 22-50). Cambridge: Cambridge University Press. Disponible en: https://doi.org/10.1017/CBO9780511628511.004.

Bianculli, A. (en prensa). Latin American regionalism: Old, new, post or overlapping? En T. Börzel y T. Risse (eds.). The Oxford handbook of comparative regionalism. Oxford: Oxford University Press.

Bruszt, L. y McDermott, G. (2009). Transnational integration regimes as development programmes. En L. Bruszt y R. Holzhacker (eds.). The transnationalization of economies, States and societies: New challenges for governance in Europe. Berlin: Springer. Disponible en: https://doi.org/10.1007/978-0-387-89339-6_2.

- (2014). Leveling the playing field. Transnational regulatory integration and development. Oxford: Oxford University Press. Disponible en: https://doi.org/10.1093/acprof: oso/9780198703143.001.0001.

Bruszt, L. y Palestini, S. (2016). Regional development governance. En T. Börzel y T. Risse. The Oxford handbook of comparative regionalism. Oxford: Oxford University Press.

Bull, B. y Bøås, M. (2003). Multilateral development banks as regionalising actors: The Asian Development Bank and the Inter-American Development Bank. New Political Economy, 8 (2), 245-261. Disponible en: https://doi.org/10.1080/13563460307176.

Cardoso, F. H. y Faletto, E. (1979). Dependency and development in Latin America. Berkeley, CA: University of California Press.

Carpenter, D., Alavi, R. y Zulkifli, I. (2013). Regional development cooperation and narrowing the development gap in ASEAN. En M. McGillivray y D. Carpenter (eds.). Narrowing the development gap in ASEAN: Drivers and policy options (pp. 134-177). Abingdon: Routledge.

CEPAL (1959). The Latin American Common Market. Santiago: General Secretariat Economic Commission for Latin American and the Caribbean.

- (1994). Open Regionalism in Latin American and the Caribbean. Economic integration as a contribution to changing production patterns with social equity. Santiago: CEPAL. (2014). Regional integration towards an inclusive value chain strategy. Santiago: CEPAL. (2015). Panorama de la inserción internacional de América Latina y el Caribe. Santiago: CEPAL.

Cimoli, M., Dosi, G. y Stiglitz, J. E. (2011). Industrial policy and development: The political economy of capabilities accumulation. Oxford: Oxford University Press. 
Comisión Europea. (1997). Agenda 2000: For a stronger and wider Union. Bruselas: Comisión Europea.

Culpeper, R. (1997). Titants or Behemoths? London: Lynne Rienner Publishers.

Dabène, O. (2009). The politics of regional integration. Theoretical and comparative explorations. New York: Palgrave McMillan.

(2012). Consistency and resilience through cycles of repoliticization. En P. Riggirozzi y D. Tussie (eds.). The rise of post-hegemonic regionalism. The case of Latin America (pp. 41-64). London: Springer. Disponible en: https://doi.org/10.1007/978-94-007-2694-9_3.

De Andrade Correa, F. (2010). Regional integration and development. En M. T. Franca Filho, L. Lixinski y M. B. Olmos Giupponi (eds.). The law of MERCOSUR (pp. 395-412). Oxford: Hart Publishing.

Delors, J. (1989). Report on Economic and Monetary Union in the European Community. Brussels: European Commission, Committee for the Study of Economic and Monetary Union.

Dent, C. M. (2008). The Asian Development Bank and developmental regionalism in East Asia. Third World Quarterly, 29 (4), 767-786. Disponible en: https://doi.org/10.1080/ 01436590802052714.

Dent, C. M. y Richter, P. (2011). Sub-regional cooperation and developmental regionalism: the Case of BIMP-EAGA. Contemporary Southeast Asia, 33 (1), 29-55. Disponible en: https://doi.org/10.1355/cs33-1b.

Djelic, M. L. y Sahlin-Andersson, K. (eds.) (2006). Transnational governance: Institutional dynamics of regulation. Cambridge: Cambridge University Press. Disponible en: https:// doi.org/10.1017/CBO9780511488665.

Dosman, E. (2006). Raúl Prebisch: Power, principle and ethics of development. Buenos Aires: INTAL.

ECLAC, E. D. D. (2012). Infrastructure for regional integration. Santiago de Chile: Naciones Unidas.

Escobar, A. (1995). Encountering development. The making and unmaking of the Third World. Princeton: Princeton University Press.

Estevadeordal, A., Frantz, B. y Nguyen, T. R. (2004). Regional public goods: From theory to practice. Washington, DC: Asian Development Bank and Inter-American Development Bank.

European Commission (1997). Agenda 2000: For a stronger and wider Union. Brussels: European Commission.

Gardini, G. L. y Lambert, P. (2011). Latin American foreign policies. New York: Palgrave Macmillan. Disponible en: https://doi.org/10.1057/9780230118270.

Helleiner, E. (2009). The development mandate of international institutions: Where did it come from? Studies in Comparative International Development, 44 (3), 189-211. Disponible en: https://doi.org/10.1007/s12116-009-9042-3.

Héritier, A. (2008). Causal explanation. En D. Della Porta y M. Keating (eds.). Approaches and methodologies in the social sciences. A pluralist perspective. Cambridge: Cambridge University Press. Disponible en: https://doi.org/10.1017/CBO9780511801938.005.

Kararach, G. (2014). Development policy in Africa: Mastering the future? Basingstoke: Palgrave Macmillan. Disponible en: https://doi.org/10.1057/9781137360595. 
Keating, M. (2008). Thirty years of territorial politics. West European Politics, 31 (12), 60-81. Disponible en: https://doi.org/10.1080/01402380701833723.

Lapavitsas, C. y Noguchi, M. (2005). Beyond market-driven development: Drawing on the experience of Asia and Latin America. Abingdon: Routledge.

Larrain, J. (1989). Theories of development: Capitalism, colonialism, and dependency. Cambridge: Polity Press.

Lenz, T., Bezuijen, J., Hooghe, L. y Marks, G. (2014). Patterns of international organization. Task specific vs. general purpose. Robert Schuman Centre for Advanced Studies Research Paper RSCAS 2014/128.

Malamud, A. (2003). Presidentialism and Mercosur: A hidden cause for a successful experience. En F. Laursen (ed.). Comparative regional integration: theoretical perspectives (pp. 53-73). Aldershot: Ashgate.

Malamud, A. (2005). Mercosur turns 15: Between rising rhetoric and declining achievement. Review of International Affairs, 18 (3), 421-36. Disponible en: https://doi.org/10.1080/ 09557570500238068 .

— (2008). Jefes de Gobierno y procesos de integración: las experiencias de Europa y América Latina. En P. De Lombaerde, S. Kochi y J. Briceño-Ruiz (eds.). Del regionalismo latinoamericano a la integración interregional (pp. 137-162). México: Siglo XXI.

- (2013). Overlapping regionalism, no integration: Conceptual issues and the Latin American experiences. RSCAS Working Paper, 2013/20.

Mansfield, E. D. y Milner, H. (1997). The political economy of regionalism. New York: Columbia University Press.

Mattli, W. (1999). The logic of regional integration: Europe and beyond. Cambridge: Cambridge University Press. Disponible en: https://doi.org/10.1017/CBO9780511756238.

McGillivray, M. y Carpenter, D. (eds.) (2013). Narrowing the development gap in ASEAN: Drivers and policy options. Abingdon: Routledge.

Neto, O. A. (2011). De Dutra a Lula. A condução e os determinantes da política externa brasileira. Rio de Janeiro: Elsevier.

Nolte, D. (2014). Latin America's new regional architecture: A cooperative or segmented regional governance complex? RCAS Working Papers 2014/89.

OCDE (2012). Latin American economic outlook. Transforming the State for development. París: OCDE.

OMC y OCDE (2013). Aid for trade at a glance: Connecting to value chains. Paris: OCDE.

Palestini, S. (2012). Regímenes de integración regional: la construcción institucional de los mercados del sur global. Revista de Sociología, (27), 55-78.

- (2016). Energía de baja intensidad: gobiernos, mercados e instituciones en el regionalismo energético de América del Sur. Caderno CRH, 29 (3), 107-123. Disponible en: https://doi.org/10.1590/S0103-49792016000400008.

Palestini, S. y Agostinis, G. (2015). Constructing regionalism in South America: the cases of sectoral cooperation on transport infrastructure and energy. Journal of International Relations and Development. Disponible en: https://doi.org/10.1057/jird.2015.15.

Perroux, F. (1955). Note sur la Notion de Pôle de Croissance. Économie appliquée, 8, 307-320. PNUD (1993). Informe de desarrollo humano 1993. New York: PNUD. 
Prebisch, R. (1963). Hacia una dinámica del desarrollo latinoamericano. México DF: Fondo de Cultura Económica.

Riggirozzi, P. y Tussie, D. (2012). The rise of post-hegemonic regionalism: The case of Latin America. London: Springer. Disponible en: https://doi.org/10.1007/978-94-007-2694-9.

Rist, G. (2006). The history of development from Western origins to global faith. London: Zed Books.

Rodrik, D., Subramanian, A. y Trebbi, F. (2004). Institutions Rule: The Primacy of Institutions Over Geography and Integration in Economic Development. Journal of Economic Growth, 9 (2), 131-165. Disponible en: https://doi.org/10.1023/B:JOEG.0000031425.72248.85.

Rostow, W. W. (1966). The process of economic growth. New York: W. W. Norton.

Sanahuja, J. A. (2012). Post-liberal regionalism in South America: The case of UNASUR. Firenze: IUE-Working Papers.

Sanahuja, J. A. et al. (2015). Beyond 2015: Perspectives and proposals for development cooperation between the European Union and Latin America and the Caribbean. Hamburg: EU-LAC Foundation.

SEGIB (2014). Informe de la cooperación sur-sur en Iberoamérica 2013-2014. Madrid: Secretaría General Iberoamericana.

(2015). Informe de la cooperación sur-sur en Iberoamérica 2015. Madrid: Secretaría General Iberoamericana.

Sloan, J. W. (1971). The strategy of developmental regionalism: Benefits, distribution, obstacles, and capabilities. Journal of Common Market Studies, 10 (2), 138-162. Disponible en: https://doi.org/10.1111/j.1468-5965.1971.tb00649.x.

Stiglitz, J. E. y Charlton, A. (2006). Aid for Trade. International Journal of Development Issues, 5 (2), 1-41.

Strange, S. (1982). Cave! Hic dragones: A critique of regime analysis. International Organization, 36 (2), 479-496. Disponible en: https://doi.org/10.1017/S0020818300019020.

Tinbergen, J. (1965). International economic integration. Amsterdam: Elsevier.

UNCTAD (2013). Economic development in Africa Report 2013. New York: United Nations. Disponible en: https://doi.org/10.18356/2235335a-en.

Vennesson, P. (2008). Case studies and process tracing: Theories and practice. En D. Della Porta y M. Keating (eds.). Approaches and methodologies in the social sciences. A pluralist perspective. Cambridge: Cambridge University Press. Disponible en: https://doi. org/10.1017/CBO9780511801938.013.

Vivares, E. (2013). Financing regional growth and the Inter-American Development Bank: The case of Argentina. Abingdon: Routledge.

Wade, R. (2011). The market as means rather than master: The crisis of development and the future role of the State. En S. R. Khan y J. Christiansen (eds.). Towards new developmentalism: Markets as means rather than master (pp. 21-46). Abingdon: Routledge. 
ANEXO. Lista de entrevistados

\begin{tabular}{|c|c|c|}
\hline Nombre & Cargo / posición & $\begin{array}{c}\text { Lugar de la } \\
\text { entrevista }\end{array}$ \\
\hline $\begin{array}{l}\text { Samuel Pinheiro } \\
\text { Guimarães }\end{array}$ & Former General Secretary of Itamaraty. & Brasília \\
\hline $\begin{array}{l}\text { Juan Carlos } \\
\text { Pakinson }\end{array}$ & $\begin{array}{l}\text { Director of Economic Relations of South } \\
\text { America, Itamaraty. }\end{array}$ & Brasília \\
\hline Renato Baumann & $\begin{array}{l}\text { Director of Studies on Economic and } \\
\text { International Policy Relations, at the Institute } \\
\text { of Applied Economic Research (IPEA). } \\
\text { Former official Ministry of Planning, Brazil. }\end{array}$ & Brasília \\
\hline Ernesto Carrara & $\begin{array}{l}\text { National Coordinator from Brazil at IIRSA } \\
\text { and COSIPLAN. Official Ministry of } \\
\text { Planning, Brazil. }\end{array}$ & Brasília \\
\hline Welber Barral & $\begin{array}{l}\text { Former Foreign Trade Secretary at Brazil's } \\
\text { Ministry of Development, Industry and } \\
\text { Foreign Trade, Brazil. }\end{array}$ & Brasília \\
\hline Sergio Leo & $\begin{array}{l}\text { Journalist of Valor Econômico, specialist in } \\
\text { Brazilian foreign policy. }\end{array}$ & Brasília \\
\hline Leandro Couto & $\begin{array}{l}\text { Director Department of Management, } \\
\text { Ministry of Planning, Brazil. }\end{array}$ & Brasília \\
\hline $\begin{array}{l}\text { Helena de } \\
\text { Almeida } \\
\text { Cantizano }\end{array}$ & $\begin{array}{l}\text { Assessor of Foreign Affairs Ministry of } \\
\text { Mining and Energy, Brazil. Representative } \\
\text { of Brazil at the South American Energy } \\
\text { Council, UNASUR. }\end{array}$ & Brasília \\
\hline Darc Costa & $\begin{array}{l}\text { President of the Federation of the Chambers } \\
\text { of Commerce and Industry of South America. } \\
\text { Former Vice-President of the BNDES. }\end{array}$ & Rio de Janeiro \\
\hline $\begin{array}{l}\text { Luiz Alfredo } \\
\text { Salomão }\end{array}$ & $\begin{array}{l}\text { School of Public Policy, Federal University of } \\
\text { Rio de Janeiro. }\end{array}$ & Rio de Janeiro \\
\hline Raphael Padula & $\begin{array}{l}\text { Professor of Political Economy at the Federal } \\
\text { University of Rio de Janeiro. }\end{array}$ & Rio de Janeiro \\
\hline José Tavarés & $\begin{array}{l}\text { Director Center of Studies in Integration and } \\
\text { Development (CINDES). }\end{array}$ & Rio de Janeiro \\
\hline $\begin{array}{l}\text { Claudia Amarante/ } \\
\text { Leonardo Botelho }\end{array}$ & $\begin{array}{l}\text { Department of International Institutional } \\
\text { Relations (BNDES). }\end{array}$ & Rio de Janeiro \\
\hline
\end{tabular}


$\ldots / \ldots$

\begin{tabular}{|c|c|c|}
\hline Nombre & Cargo / posición & $\begin{array}{l}\text { Lugar de la } \\
\text { entrevista }\end{array}$ \\
\hline Nivalde de Castro & $\begin{array}{l}\text { Coordinator Group of Studies on the Electric } \\
\text { Sector, Federal University of Rio de Janeiro. }\end{array}$ & Rio de Janeiro \\
\hline Ricardo Gorini & $\begin{array}{l}\text { Director of Economic and Energy Studies } \\
\text { at the Energy Research Enterprise (EPE), } \\
\text { Brazil. }\end{array}$ & Rio de Janeiro \\
\hline Ildo Sauer & $\begin{array}{l}\text { Former director of the Department of Gas } \\
\text { and Energy of Petrobras. }\end{array}$ & São Paulo \\
\hline José Luiz Pimienta & $\begin{array}{l}\text { Coordinator International Negotiations, } \\
\text { Industrial Federation of São Paulo (FIESP) }\end{array}$ & São Paulo \\
\hline $\begin{array}{l}\text { Roberto } \\
\text { Cavalcanti } \\
\text { / Maria Celina de } \\
\text { Azevedo. }\end{array}$ & $\begin{array}{l}\text { Director Department of Infrastructure, } \\
\text { Federation of Industries of the State of São } \\
\text { Paulo (FIESP). }\end{array}$ & São Paulo \\
\hline Janina Onuki & $\begin{array}{l}\text { Institute of International Relations, } \\
\text { University of São Paulo. }\end{array}$ & São Paulo \\
\hline Terra Budini & $\begin{array}{l}\text { Secretary of International Relations, Worker's } \\
\text { Party (PT). }\end{array}$ & São Paulo \\
\hline Deyse Ventura & $\begin{array}{l}\text { Institute of International Relations, } \\
\text { University of São Paulo. }\end{array}$ & São Paulo \\
\hline Giorgio Romano & $\begin{array}{l}\text { Professor of International Relations at the } \\
\text { Federal University of ABC, Brazil. }\end{array}$ & São Paulo \\
\hline Ricardo Lagos & Former President of the Republic, Chile. & $\begin{array}{l}\text { Santiago, } \\
\text { Chile }\end{array}$ \\
\hline $\begin{array}{l}\text { Juan Gabriel } \\
\text { Valdés }\end{array}$ & Former Minister of Foreign Affairs of Chile. & $\begin{array}{l}\text { Santiago, } \\
\text { Chile }\end{array}$ \\
\hline Rigoberto García & $\begin{array}{l}\text { Ministry of Public Works, Chile. National } \\
\text { Coordinator at IIRSA/COSIPLAN. }\end{array}$ & $\begin{array}{l}\text { Santiago, } \\
\text { Chile }\end{array}$ \\
\hline Carolina Muñoz & $\begin{array}{l}\text { National Delegate in UNASUR. Department } \\
\text { of Multilateral Affairs, Ministry of Foreign } \\
\text { Affairs, Chile. }\end{array}$ & $\begin{array}{l}\text { Santiago, } \\
\text { Chile }\end{array}$ \\
\hline Gonzalo García & $\begin{array}{l}\text { Representative of Chile in the negotiations } \\
\text { of the South American Defense Council, of } \\
\text { UNASUR. }\end{array}$ & $\begin{array}{l}\text { Santiago, } \\
\text { Chile }\end{array}$ \\
\hline
\end{tabular}


$\ldots / \ldots$

\begin{tabular}{|c|c|c|}
\hline Nombre & Cargo / posición & $\begin{array}{c}\text { Lugar de la } \\
\text { entrevista }\end{array}$ \\
\hline Marcela Espinoza & $\begin{array}{l}\text { Department of Borders and Limits, Ministry } \\
\text { of Foreign Affairs, Chile. Representative of } \\
\text { Chile at COSIPLAN. }\end{array}$ & $\begin{array}{l}\text { Santiago, } \\
\text { Chile }\end{array}$ \\
\hline Alfredo Forti & $\begin{array}{l}\text { Director Center of Strategies Studies of } \\
\text { the South American Defense Council, } \\
\text { UNASUR. }\end{array}$ & $\begin{array}{c}\text { Buenos Aires, } \\
\text { Argentina }\end{array}$ \\
\hline Pablo Carvajal & $\begin{array}{l}\text { Ministry of Energy, Ecuador. Representative } \\
\text { of Ecuador at the Energy Council. }\end{array}$ & $\begin{array}{l}\text { Quito, } \\
\text { Ecuador }\end{array}$ \\
\hline Vitorio Oxilia & $\begin{array}{l}\text { Director Latin American Organization of } \\
\text { Energy (OLADE), Quito, Ecuador. }\end{array}$ & $\begin{array}{l}\text { Quito, } \\
\text { Ecuador }\end{array}$ \\
\hline César Montufar & Congressman, Ecuador. & $\begin{array}{l}\text { Quito, } \\
\text { Ecuador }\end{array}$ \\
\hline Kintto Lucas & $\begin{array}{l}\text { Former Director of Communication, } \\
\text { General Secretary of UNASUR. }\end{array}$ & $\begin{array}{l}\text { Quito, } \\
\text { Ecuador }\end{array}$ \\
\hline Adrián Bonilla & $\begin{array}{l}\text { Director of the Latin American Faculty of } \\
\text { Social Science (FLACSO). }\end{array}$ & $\begin{array}{l}\text { Quito, } \\
\text { Ecuador }\end{array}$ \\
\hline $\begin{array}{l}\text { Fernando Simas } \\
\text { Magalhães }\end{array}$ & Ambassador of Brazil in Ecuador. & $\begin{array}{l}\text { Quito, } \\
\text { Ecuador }\end{array}$ \\
\hline Francisco Carrión & Former Chancellor of Ecuador. & $\begin{array}{l}\text { Quito, } \\
\text { Ecuador }\end{array}$ \\
\hline Fredy Rivera & $\begin{array}{l}\text { Representative of Ecuador in the negotiations } \\
\text { of the South American Defense Council of } \\
\text { UNASUR. }\end{array}$ & $\begin{array}{l}\text { Quito, } \\
\text { Ecuador }\end{array}$ \\
\hline Humberto Molina & $\begin{array}{l}\text { Diplomatic Stuff General Secretariat of } \\
\text { UNASUR. }\end{array}$ & $\begin{array}{l}\text { Quito, } \\
\text { Ecuador }\end{array}$ \\
\hline Mauro Marcondes & $\begin{array}{l}\text { Inter-American Development Bank (IIRSA } \\
\text { coordinator, 2003-2008) }\end{array}$ & $\begin{array}{l}\text { Online } \\
\text { interview }\end{array}$ \\
\hline Ricardo Terrazas & $\begin{array}{l}\text { Director of Projects South American. Latin } \\
\text { American Development Bank (CAF) }\end{array}$ & $\begin{array}{l}\text { Online } \\
\text { interview }\end{array}$ \\
\hline Paulo Silveira & Former Secretary of Planning. Brazil. & $\begin{array}{l}\text { Online } \\
\text { interview }\end{array}$ \\
\hline
\end{tabular}

